\title{
Forensic evaluation of sex estimation via measurements of adult index and ring finger lengths using postmortem computed tomography
}

\author{
Tomoya Ikeda ${ }^{1,2^{*}}$ (D), Kazunori Miyamoto ${ }^{2}$, Naoto Tani ${ }^{1,2}$, Shigeki Oritani ${ }^{1}$, Tomomi Michiue ${ }^{1,2}$, Fumiya Morioka ${ }^{1}$
} and Takaki Ishikawa ${ }^{1,2}$

\begin{abstract}
Background: Sex estimation from fragmented or isolated human bones found during excavations is imperative not only in the field of forensics but also paleoanthropology. This study investigated the possibility of sex estimation from computed tomography $(\mathrm{CT})$ data for the lengths of the index and ring fingers. The scans were obtained using a multislice ECLOS-16 CT scanner (Hitachi Medical Co., Tokyo, Japan), and the images were analyzed using a SYNAPSE VINCENT volume analyzer (Fujifilm Medical Co., Tokyo, Japan). For 205 cases, the authors measured the total length of the distal, middle, and proximal phalanges $(P)$ and of the metacarpal bones for the index and ring fingers of both hands. Right heart serum testosterone and estradiol levels in 92 cases were also measured by an electrochemiluminescence immunoassay and a chemiluminescence immunoassay, respectively.

Result: The difference in $\mathrm{P}$ between the index and ring fingers was significantly greater in men than in women for both hands; receiver operating characteristic analysis showed an optimal cutoff of $6.0 \mathrm{~mm}$ (sensitivity, 0.64 and specificity, 0.64). Blood testosterone levels were moderately correlated with this difference.

Conclusion: A value of $6.0 \mathrm{~mm}$ for the ring finger-index finger difference for the left hand distinguished men from women, and these results are affected by testosterone levels. The findings from this report in the field of forensics and paleoanthropology indicated that the $\mathrm{CT}$ data-assessed morphometry of the phalanges could be used as an objective index for sex estimation.
\end{abstract}

Keywords: Forensic science, Forensic anthropology, Sex estimation, Computed tomography, Index finger length, Ring finger length, Japanese population

\section{Background}

Forensic anthropology, along with DNA analyses of sex and genetic polymorphisms, is essential for the estimation of sex, age, and stature in the identification of human remains and single bones (Aldegheri and Agostini 1993; Duyar and Pelin 2003; Ozaslan et al. 2003; Petrovecki et al. 2007; Zeybek et al. 2008). Moreover, paleoanthropology enables the estimation of sex from a bone fragment and/or isolated human bones from excavations (Alarcon et al. 2016;

\footnotetext{
* Correspondence: ikeda.tomoya@med.osaka-cu.ac.jp

${ }^{1}$ Department of Legal Medicine, Osaka City University Medical School, Osaka 545-8585, Japan

${ }^{2}$ Forensic autopsy section, Medico-legal Consultation and Postmortem Investigation Support Center (MLCPI-SC), Osaka, Japan
}

Slizewski et al. 2013). However, one of the greatest limitations to the application of the anatomical sex estimation method is its inability to evaluate some of the skeletal elements required for the calculation. Indeed, a major challenge in analyzing skeletal remains, particularly archaeological samples, is the high incidence of missing and/or non-measurable elements (Auerbach 2011). Therefore, there are a number of factors that contribute to the variability in the preservation and use of archaeological human remains for research. In this process, radiology is used to detect anatomical characteristics, specific bone pathologies, and foreign bodies (including surgical materials), as well as identifying sex-related differences and age-dependent 
changes, and providing measurements for stature estimation (Hasegawa et al. 2009; Rainio et al. 2001). However, until recently, it has been difficult to make such assessments from a single small bone from a cadaver, especially given that the bone may have been moved away from the remainder of the cadaver, such as by an animal or insects (Campobasso and Introna 2001).There is therefore a lack of scientific data about small bones in the field of forensic medicine.

In addition to conventional radiology, computed tomography (CT) may be useful for the documentation and reconstruction of skeletal data in autopsy routines. Postmortem imaging has been reported as useful for identifying individuals, and investigations are ongoing about the practicality of imaging various bones for the estimation of sex, height, and weight (Giurazza et al. 2012; Hishmat et al. 2014; Torimitsu et al. 2014a; Torimitsu et al. 2014b; Torimitsu et al. 2015c). Several studies have demonstrated the successful application of CT to virtual bone measurement for estimating sex and stature (Djorojevic et al. 2014; Hishmat et al. 2015; Inamori-Kawamoto et al. 2016; Macaluso and Lucena 2014; Rodriguez et al. 2014; Torimitsu et al. 2015b; Torimitsu et al. 2014c; Torimitsu et al. 2015a; Verhoff et al. 2008).

Previous studies in the forensic science field have reported osteometric data about index and ring finger lengths for sex estimation in different modern populations (Agnihotri et al. 2015; Kanchan et al. 2010; Kanchan and Pradeep Kumar 2010; Kanchan et al. 2010; Krishan et al. 2013), but, as yet, such studies have not involved postmortem CT data. Furthermore, to the best of our knowledge, there have been no published studies in the forensic science field that have investigated the influence of sex hormones (such as androgen and estrogen) on the lengths of the index and ring fingers. In the present study, therefore, the authors investigated the possibility of sex estimation from CT data about index and ring finger lengths, as well as the influence of sex hormones on finger length.

\section{Materials and methods Postmortem CT data.}

Postmortem CT scans are performed at our institution immediately before autopsy as part of the scope of routine casework such as personal identification, injury tact, and pathophysiological analysis. In this study, we used autopsy cases of post-adolescent Japanese subjects (age $\geq 20$ years) of known sex, age, height, weight, and stature, for which complete finger bone CT data were available. Cases with advanced decomposition, evident fracture, destruction, or advanced osteoarthrosis were excluded. Cases were excluded if the details regarding sex and height could not be definitively verified due to postmortem destruction, and no case included in this study qualified for exclusion. Samples for 205 cases
(102 men and 103 women; age range, 20-95 years; median age, 60 years) were collected during a 5-year period from July 2011 to September 2015 (Table 1).

Postmortem interval, defined as the time elapsed from estimated time of death to autopsy ranged from 10 to $370 \mathrm{~h}$ (median, $33 \mathrm{~h}$ ) and was calculated based on autopsy findings, case history, and circumstantial evidence; thus, possible error in postmortem interval ranged up to hours depending on elapsed time in cases of unwitnessed deaths. Necessary data were extracted from autopsy documents, pathological findings, and circumstantial evidence.

Whole-body PMCTs were routinely performed immediately before forensic autopsy using a 16-row multidetector CT scanner (ECLOS, Hitachi Medical Co., Tokyo, Japan) as part of routine casework. Spiral CT was performed using the following conditions: $120 \mathrm{kV}$; $250 \mathrm{~mA}$; 1.25-pitch factor, $2.5 \times 4 \mathrm{~mm}$ collimation, and $1.0 \times$ $1.25 \mathrm{~mm}$ thickness; field of view, $500 \mathrm{~mm}$. A CT data analysis system, volume analyzer Synapse Vincent (Fujifilm Medical Co., Ltd., Tokyo, Japan), was used to reconstruct three-dimensional (3D) images of the finger bone in situ for virtual length measurement which was extracted by manual cursoring. These analyses were performed by two forensic pathologists and one radiographer. The reproducibility of virtual reconstruction and measurement was checked by two independent observers. CT attenuation [Hounsfield units (HUs)] was performed using the correlation of $\mathrm{HU}$ with bone-specific length.

\section{Measurements.}

For each finger (left and right index and ring fingers), the authors measured the following: $P$, the length from the bottom prominence to the tip of the distal phalanx (i.e., the total length of the distal, middle, and proximal phalanges); $M$, the length of the metacarpal bones in the longitudinal direction; and $P+M$, the total of lengths $P$ and $M$ (Fig. 1a-c). Moreover, the differences in $P, M$ and $P+M$ between the finger $(\mathrm{R})$ and index finger (I) were calculated for each hand $(\mathrm{R}-\mathrm{I})$. The analysis tested differences between the sexes for all these lengths and their correlations with the levels of sex hormones testosterone and estradiol.

\section{Biochemical analyses.}

Testosterone concentrations in serum from the right heart were measured by electrochemiluminescence immunoassay (Ezaki et al. 2010) For this measurement, the clinical serum reference intervals were $0.54-10.10 \mathrm{ng} / \mathrm{ml}$ (median $3.42 \mathrm{ng} / \mathrm{ml}$ ) for the men and $0.20-8.55 \mathrm{ng} / \mathrm{ml}$ (median $1.20 \mathrm{ng} / \mathrm{ml}$ ) for the women. Estradiol concentrations in serum from the right heart were measured by chemiluminescence immunoassay (Dettling et al. 2008), with clinical serum reference intervals of $20-2000 \mathrm{pg} / \mathrm{ml}$ (median $278.5 \mathrm{pg} / \mathrm{ml}$ ) for the men and 20-1765 pg/ml 
Table 1 Case profiles

\begin{tabular}{|c|c|c|c|c|c|c|c|c|c|c|c|c|c|}
\hline \multirow[t]{2}{*}{ Cause of death } & \multirow{2}{*}{$\begin{array}{l}\text { n (Male / } \\
\text { Female) }\end{array}$} & \multicolumn{3}{|c|}{ Age (years) } & \multicolumn{3}{|c|}{ Height $(\mathrm{cm})$} & \multicolumn{3}{|c|}{ Weight (kg) } & \multicolumn{3}{|c|}{ Postmortem time (h) } \\
\hline & & Median & Min & $\operatorname{Max}$ & Median & Min & $\operatorname{Max}$ & Median & Min & $\operatorname{Max}$ & Median & Min & $\operatorname{Max}$ \\
\hline Blunt injury & $59(35 / 24)$ & 62 & 20 & 93 & 161 & 138 & 180 & 54.5 & 30.2 & 105 & 34 & 14 & 145 \\
\hline Sharp instrument injury & $13(7 / 6)$ & 55 & 38 & 86 & 160 & 150 & 169 & 61.5 & 31.9 & 86.2 & 28 & 10 & 41 \\
\hline Drowning & $11(6 / 5)$ & 51 & 33 & 85 & 160 & 144 & 172 & 56.1 & 34.4 & 67.5 & 36 & 17 & 206 \\
\hline Fire fatalities & $2(1 / 1)$ & & 55 & 65 & & 158 & 168 & & 52.5 & 75.7 & & 17 & 24 \\
\hline Asphyxia & $22(10 / 12)$ & 49 & 21 & 86 & 164 & 143 & 174 & 54.6 & 34.6 & 73.5 & 33 & 14 & 301 \\
\hline Hypothermia & $5(1 / 5)$ & 83 & 47 & 87 & 149 & 140 & 159 & 39.9 & 30.3 & 55.7 & 39 & 26 & 110 \\
\hline Hyperthermia & $21(8 / 13)$ & 71 & 28 & 95 & 157 & 136 & 170 & 46.4 & 23.6 & 72.4 & 33 & 15 & 109 \\
\hline Sudden cardiac death & $18(10 / 8)$ & 69 & 29 & 84 & 161 & 145 & 181 & 54.3 & 43.2 & 82.3 & 35 & 16 & 181 \\
\hline Other natural death & $54(24 / 30)$ & 51 & 24 & 93 & 160 & 140 & 179 & 53.6 & 27.5 & 99.8 & 32 & 10 & 370 \\
\hline Total & $205(102 / 103)$ & 59 & 20 & 95 & 160 & 136 & 181 & 54.2 & 23.6 & 105 & 33 & 10 & 370 \\
\hline
\end{tabular}

(median $275 \mathrm{pg} / \mathrm{ml}$ ) for the women (except for any that had been pregnant at the time of death.

\section{Toxicological analyses.}

Blood carboxyhemoglobin concentrations for the fire fatalities were determined using a CO-oximeter system (Maeda et al. 1997; Maeda et al. 1996). Drugs, such as an amphetamine and antipsychotropics, were detected by gas chromatography/mass spectrometry.

\section{Statistical analyses.}

The statistical analyses were performed using Microsoft Excel and SPSS (version 17.0; SPSS, Inc., Chicago, IL, USA). The Kruskal-Wallis test, Bland-Altman plots, Pearson's correlation analysis, and Mann-Whitney $U$ tests were used, as appropriate, for nonparametric comparisons of two datasets and multiple group analyses of all examination items. Linear regression analysis was used to estimate stature based on the individual bone parameters. In these analyses, $\mathrm{p}$-values $<0.05$ were considered statistically significant. Receiver operating characteristic analysis was used to establish cutoff points for each individual bone parameter for the optimal estimation of sex (Vexler et al. 2008); cases above and below the cutoff values were deemed male and female, respectively. The accuracy of sex estimation using these cutoff values was examined by dividing the number of cases identified by the total number of cases.

\section{Results}

Relationships between bone lengths and general characteristics

There was no significant correlation between the lengths of the index or ring fingers and postmortem time $(p>0.05)$. In detail, the authors compared the postmortem period with under more than two days ( $\leq 48$ h: $n=150$, > 48 h: $n=55$ ), there was no statistical difference (left index finger: $p=0.3098$, left ring

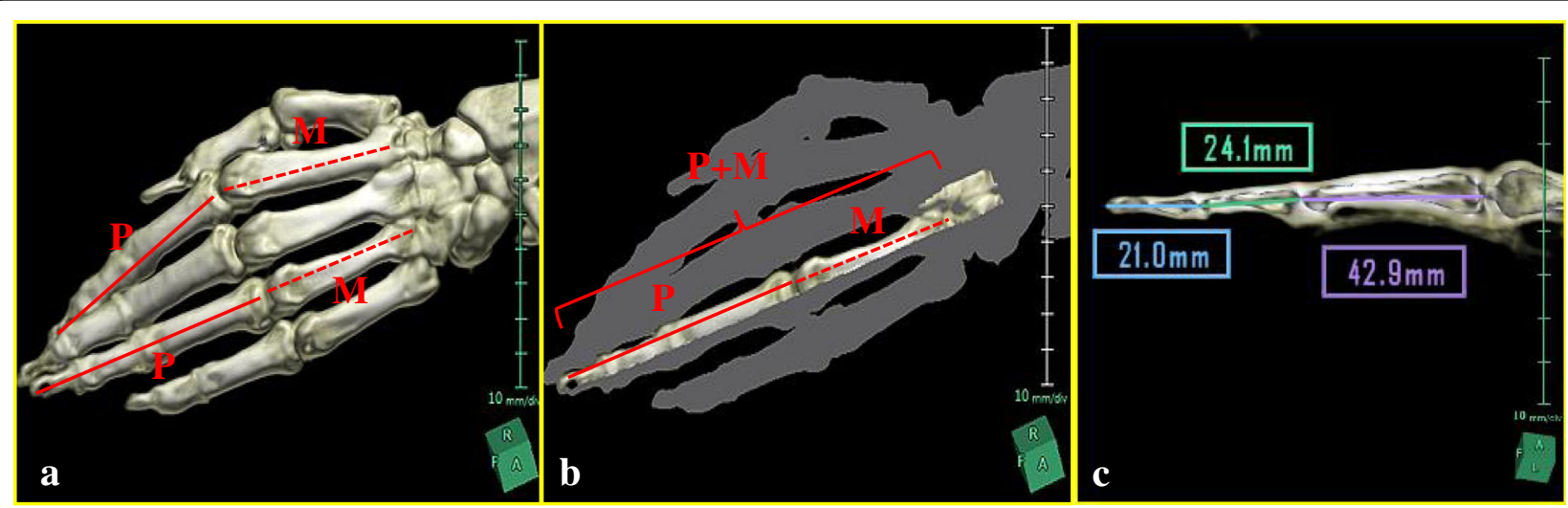

Fig. 1 Measurements of finger lengths by computed tomography and the computer analyzer system. Red solid line: P, the total length of the distal, middle, and proximal phalanges. Red broken line: $M$, the length of the metacarpal bones in the longitudinal direction. a-c The figures show method for measurements. $P+M$ : the total of lengths $P$ and $M$ 
finger: $p=0.5318$, right index finger: $p=0.3638$, right ring finger $p=0.3186$ ). Furthermore, about the same person (84 years, male, height $168 \mathrm{~cm}$, body weight 59.6 $\mathrm{Kg}$ ), as a result of having performed the measurement (24 $\mathrm{h}$ later) twice, there was not the difference that was slight to a peripheral bone (first time: $16.70 \mathrm{~mm}$, second time $16.70 \mathrm{~mm}$ ), middle phalanx (first time: $21.30 \mathrm{~mm}$, second time $21.30 \mathrm{~mm}$ ), proximal phalanx (first time: $40.10 \mathrm{~mm}$, second time $40.1 \mathrm{~mm})$. On the other hand, after having left the same person unattended posthumously for several months, it is not a permissible thing ethically to measure the length of the finger again. Therefore, the authors were not able to examine a post mortem change in detail.

$P$ (the total length of the three phalanges) was moderately to strongly correlated with height $(r=0.439-0.545$, $p<0.0001)$ for the left and right index and ring fingers of both sexes. However, $P$ showed no significant correlation with body mass index, bodyweight, or age $(p>0.05)$.

There were strong correlations between $P$ for the ring and index fingers in both men (left: $r=0.847, p<0.0001$ and right: $r=0.879, p<0.0001$ ) and women (left: $r=0.854$, $p<0.0001$ and right: $r=0.887, p<0.0001$; Fig. 2).

$M$ (the length of the metacarpal bones) was slightly to moderately correlated with height $(r=0.534-0.702$, $p<0.0001)$ and weight $(r=0.217-0.330, p<0.05)$ for the left and right index and ring fingers of both sexes. In men, but not women, there was a slight negative correlation between $M$ and age (left index, $r=0.260, p<0.01$; left ring, $r=0.310, p<0.01$ and right index, $r=0.289, p<0.01$; right ring, $r=0.246, p<0.05$ ).

\section{Relationships between bone lengths and sex}

Values for $P, M$, and $P+M$ for both sexes are given in Table 2. Values of $P$ for the left and right index and ring fingers were significantly greater for the male than the female (left index, $p<0.0001$; right index, $p<0.001$; left ring, $p<0.0001$; right ring, $p<0.0001)$. Similarly, values of $M$ for the left and right index and ring fingers were significantly greater for the male than the female (left index, $p<0.0001$; right index, $p<0.0001$; left ring, $p<0.0001$; right ring, $p<0.0001)$. Moreover, $P+M$ values for the male were significantly longer than for the female (left index, $p<0.0001$ and right index, $p<0.0001$; left ring, $p<0.0001$ and right ring: male, $p<0.0001$ ).

\section{Relationships between $\mathbf{R}-\mathbf{I}$ differences and sex}

The differences in $P$ between the ring and index fingers, $\mathrm{R}$ - I, are shown in Table 3. These differences were significantly greater for the male than for the female (left, $p<0.0001$; right, $p<0.001$ ). The presence of a sex difference in the left hand was clearer when we compared $P$ between the right and left hands (Fig. 3).

However, there were no significant differences between the sexes for the $\mathrm{R}-\mathrm{I}$ difference in $M(p>0.05)$ or $P+M$ $(p>0.05$; Tables 2 and 3$)$.

\section{Cutoff values to distinguish men from women}

Figure 4 shows differences in phalangeal length (ring finger-index finger) in male and female. In the receiver operating characteristic analysis, the optimal cutoff value for distinguishing men from women was a value of $6.0 \mathrm{~mm}$ for the R-I difference in $P$ for the left hand. This showed a sensitivity of 0.64 and a specificity of 0.64 (Fig. 4). There was statistical significant difference in right and left index finger of the male $(p<0.05)$, without other fingers.

The area under the curve (AUC) in this study was 0.673 . Discriminant function equations is $-0.0004 \times{ }^{2}-$ $50.795 x+317.91=0$, The $x$-axis was a difference of the

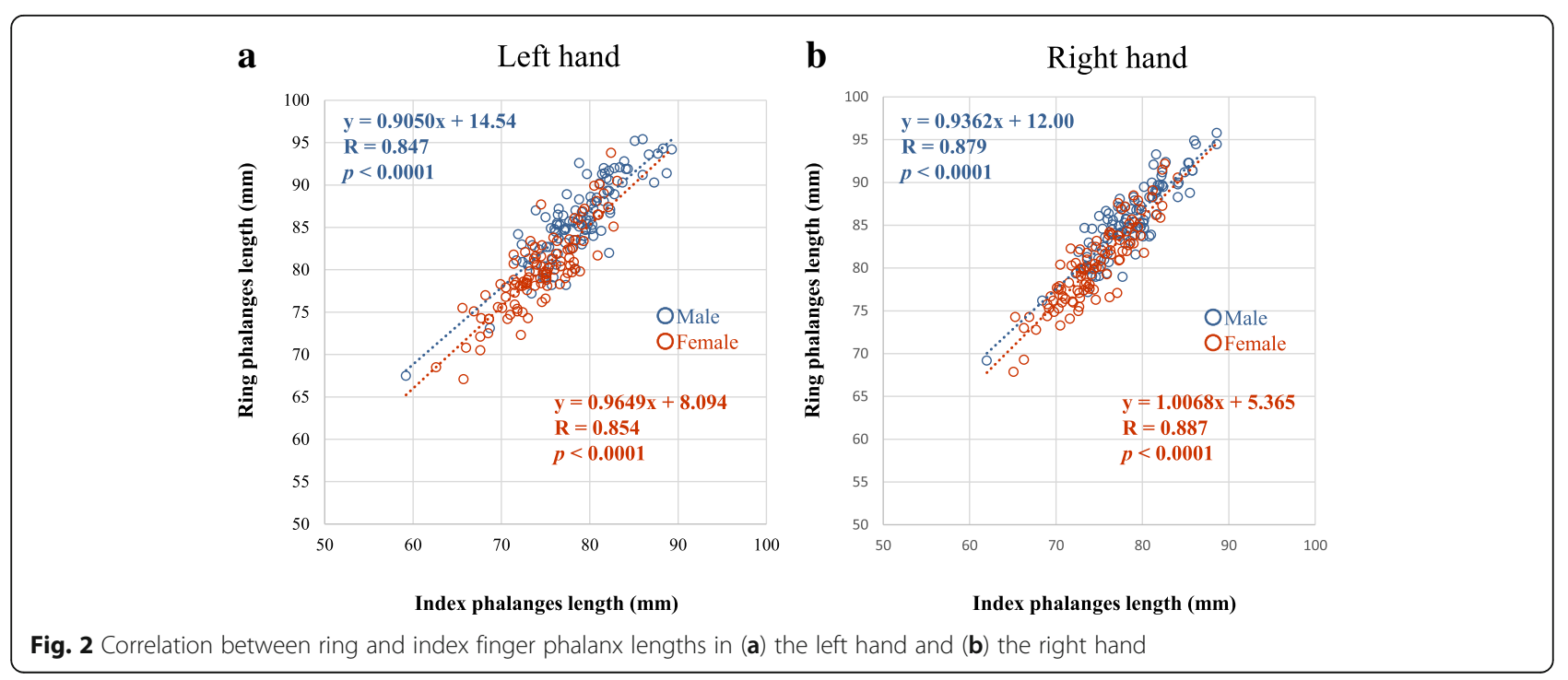


Table 2 Bone lengths

\begin{tabular}{|c|c|c|c|c|c|c|c|c|c|c|c|c|c|c|c|c|c|c|c|}
\hline \multirow[t]{3}{*}{ Finger } & \multirow[t]{3}{*}{ Sex } & \multicolumn{9}{|c|}{ Left Hand } & \multicolumn{9}{|c|}{ Right hand } \\
\hline & & \multicolumn{3}{|c|}{ Phalanx (mm) } & \multicolumn{3}{|c|}{ Metacarpal (mm) } & \multicolumn{3}{|c|}{$\begin{array}{l}\text { Total length (mm) } \\
\text { (Phalanx+Metacarpal) }\end{array}$} & \multicolumn{3}{|c|}{ Phalanx (mm) } & \multicolumn{3}{|c|}{ Metacarpal (mm) } & \multicolumn{3}{|c|}{$\begin{array}{l}\text { Total length (mm) } \\
\text { (Phalanx+Metacarpal) }\end{array}$} \\
\hline & & Med. & Min & Max & Med. & Min & Max & Med. & Min & Max & Med. & Min & Max & Med. & Min & Max & Med. & Min & Max \\
\hline \multirow[t]{2}{*}{ Index finger } & Male & 78.9 & 59.2 & 89.3 & 62.9 & 50.5 & 72.4 & 141.8 & 109.7 & 161.7 & 78.7 & 62.0 & 88.6 & 63.7 & 50.2 & 71.2 & 142.1 & 112.2 & 159.2 \\
\hline & Female & 74.5 & 62.6 & 83.1 & 60.4 & 51.0 & 69.2 & 134.4 & 116.0 & 148.2 & 74.4 & 65.1 & 84.1 & 60.3 & 50.5 & 67.3 & 134.6 & 115.6 & 149.3 \\
\hline \multirow[t]{2}{*}{ Ring finger } & Male & 85.6 & 67.5 & 95.4 & 55.4 & 42.7 & 62.9 & 140.7 & 110.2 & 157.4 & 85.5 & 69.2 & 95.8 & 54.7 & 42.9 & 61.9 & 140.0 & 112.1 & 157.7 \\
\hline & Female & 79.6 & 67.1 & 93.8 & 52.0 & 42.8 & 58.9 & 131.9 & 111.9 & 149.1 & 80.2 & 67.9 & 92.2 & 51.8 & 44.7 & 61.2 & 132.5 & 113.3 & 152.7 \\
\hline
\end{tabular}

length of the left finger, and the y-axis was a difference of the length of the right finger, and the plotted the whole data. Afterwards, the authors measured the differenced the male and female boundary line by the cluster analysis. As the results, it was $\mathrm{D}=2579.62(\mathrm{D}>0)$.

\section{Relationships between finger lengths and levels of sex hormones}

Measurements of testosterone levels in the right heart serum (postmortem period $<2$ days) of 51 male and 41 female found significantly higher levels in the male than in the female (Table 4). There was not the correlation of testosterone and finger length in the elderly male and female both finger, respectively ( $>70$ years, $p>0.05)$.

There was a slight positive association between $P$ of the left ring finger and serum testosterone in men $(n=51$, $r=0.34, p<0.05 ; \mathrm{y}=0.1472 \mathrm{x}-8.8372$, where $\mathrm{x}$ is length in $\mathrm{mm}$ and $\mathrm{y}$ is testosterone level in $\mathrm{ng} / \mathrm{ml}$ ). No significant associations with testosterone were found for $M$ for the right index and ring fingers in men, for $P+M$ in men, or for any finger lengths in women.

In the men, there was a slight correlation between serum testosterone and the $\mathrm{R}-\mathrm{I}$ difference for $P$ in the left hand $(r=0.29, p<0.05)$ although there were differences in $P$ in the right hand. In the women, there were no correlations between testosterone levels and R-I differences in $P$ (Fig. 5).

Higher testosterone levels were detected in cases with a positive $\mathrm{R}-\mathrm{I}$ difference in $P+M$ (i.e., the total length of the ring finger was longer than that for the index finger).

Measurements of right heart serum estradiol levels in 51 male and 40 female showed no significant correlation with R-I differences in $P$ for either hand.

\section{Discussion}

The smaller index to ring finger (2D:4D) ratio has been considered as a 'male finger pattern' and is associated with blood testosterone levels (Aycinena et al. 2014, Robertson et al. 2008, Warrington et al. 2018). However, there is no report that examined the sex estimation using this method in a forensic medicine field.

A lot of testosterone participating are reported in the length of the finger by sex differences so far in the field of embryology and/or life sciences. However, in the field of forensic medicine, there is no report considered about sex hormone and the length of the finger. This examination is the first report that proved that the length of the finger with the sex differences depends on testosterone in the field of forensic medicine. In this study, one of the important points includes that we do not use the long bones such as a thigh bone or the humerus. Osteoarthrosis may develop in the long bone with aging according to the indication a reviewer. However, the transformation of the bone of the finger is not caused other than the special diseases such as rheumatism, amyotrophic lateral sclerosis (ALS) or the hyperparathyroidism (Kalichman et al. 2018; Zhang W et al. 2008, Parkin Kullmann and Pamphlett, 2017, Rhara et al. 2015). In this study, effective points with the using short bone such as the finger include that there is little osteoarthrosis.

This study found moderate-to-strong correlations between height and the total lengths of the phalanges $(P)$, the total lengths of the metacarpal bones $(M)$, and $P+M$ in the index fingers of both hands. The $P, M$, and $P+M$ lengths in the index and ring fingers of both hands were longer in male than in female, and the R-I differences in $P$ in both hands were also greater in the male. However,

Table 3 Difference in lengths (ring finger-index finger)

\begin{tabular}{|c|c|c|c|c|c|c|c|c|c|c|c|c|c|c|c|c|c|c|}
\hline \multirow[t]{3}{*}{ Sex } & \multicolumn{9}{|c|}{ Left Hand } & \multicolumn{9}{|c|}{ Right hand } \\
\hline & \multicolumn{3}{|c|}{ Phalanx (mm) } & \multicolumn{3}{|c|}{ Metacarpal (mm) } & \multicolumn{3}{|c|}{$\begin{array}{l}\text { Total length (mm) } \\
\text { (Phalanx+Metacarpal) }\end{array}$} & \multicolumn{3}{|c|}{ Phalanx (mm) } & \multicolumn{3}{|c|}{ Metacarpal (mm) } & \multicolumn{3}{|c|}{$\begin{array}{l}\text { Total length (mm) } \\
\text { (Phalanx+Metacarpal) }\end{array}$} \\
\hline & Med. & Min & Max & Med. & Min & $\overline{\operatorname{Max}}$ & Med. & Min & Max & Med. & Min & Max & Med. & Min & $\operatorname{Max}$ & Med. & Min & Max \\
\hline Male & +7.3 & -0.2 & +13.8 & -8.0 & -14.3 & -1.3 & -1.1 & -7.4 & +11.0 & +7.1 & +1.3 & +11.7 & -8.6 & -15.2 & -3.1 & -1.3 & -9.5 & +6.9 \\
\hline Female & +5.6 & +0.1 & +13.2 & -8.1 & -15.1 & -2.8 & -2.3 & -10.7 & +4.4 & +6.0 & +0.0 & +10.6 & -8.6 & -13.6 & -0.4 & -2.3 & -10.9 & +3.4 \\
\hline
\end{tabular}



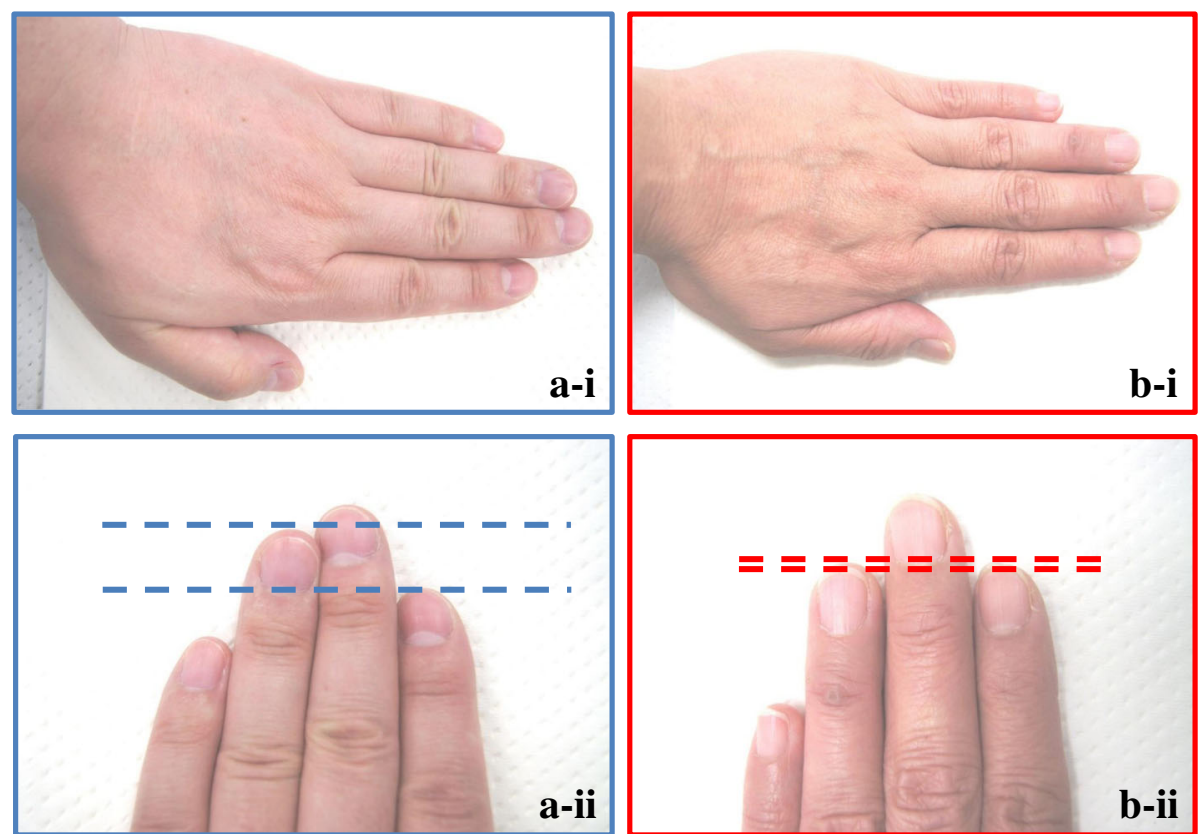

Fig. 3 Relationship between the difference in ring and index finger lengths and the sex of the individual. $\mathbf{a}$-i and $\mathbf{a}$-ii: The figures show the length of the finger of the male. $\mathbf{b}$-i and $\mathbf{b}$-ii: The figures show the length of the finger of the female

results indicated that this difference did not differ in females. This result held even for cases with a long postmortem time. Thus, the authors concluded that calculating the $\mathrm{R}-\mathrm{I}$ difference for $P$ in the ring finger is potentially useful for sex prediction in complicated forensic work in a variety of situations. In this study, the optimal cutoff value for distinguishing men from women based on the R-I difference for $P$ was estimated to be $6.0 \mathrm{~mm}$. However, our studies showed a sensitivity 0.64 , specificity 0.64 , and AUC 0.673 . Thus, it was not able to make refer to that the expected values of this study were high.

Generally, image analysis inherently low accuracy levels in contrast to DNA analysis that provides high accuracy for sex estimation. In a previous study, an accuracy of $61.7 \%$ - $87.1 \%$ was obtained using the calcaneus and talus as materials for sex estimation (Inamori-Kawamoto et al. 2016). Furthermore, sensitivity and specificity of 0.85 and 0.92 , respectively, was achieved when the authors used the human

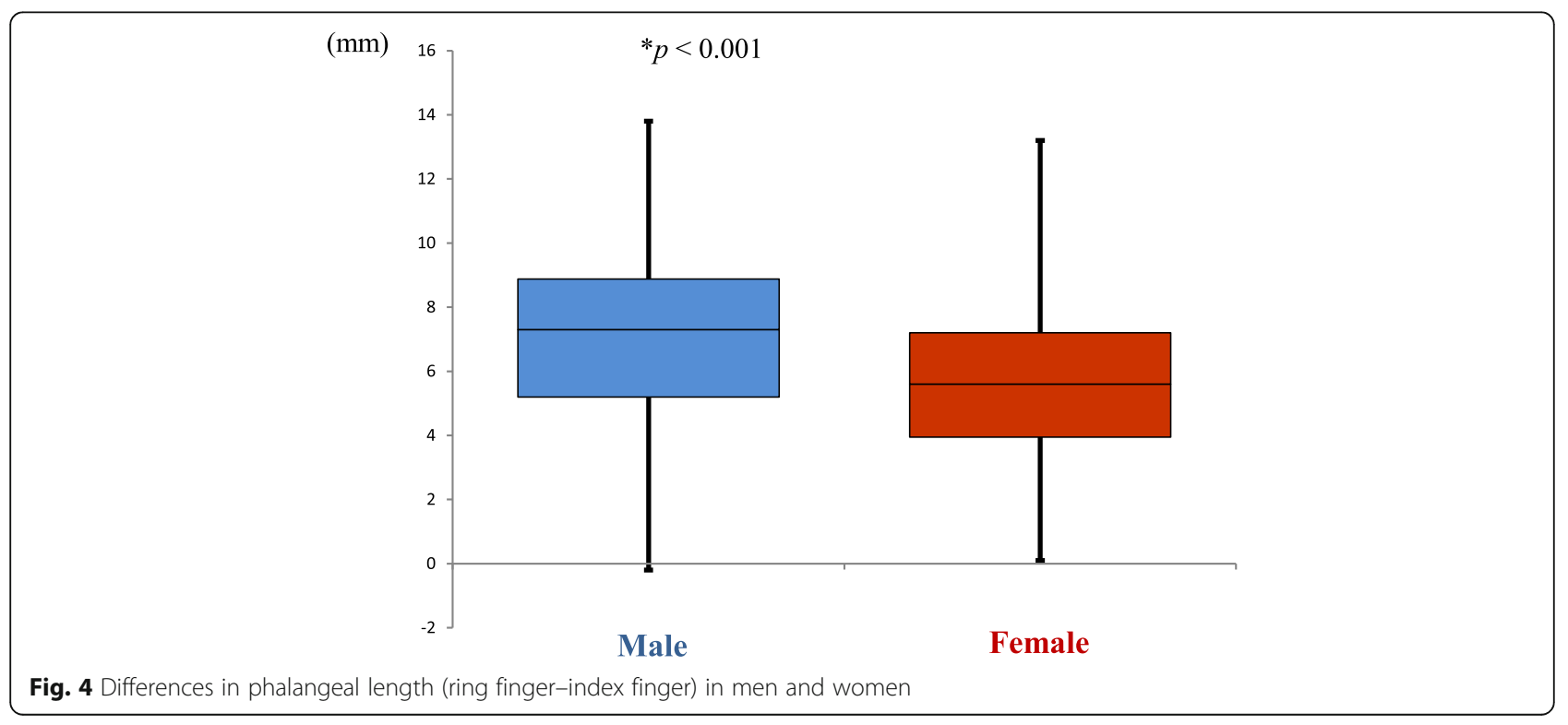


Table 4 Serum concentrations of testosterone and estradiol in the right heart

\begin{tabular}{|c|c|c|c|c|c|c|c|c|c|}
\hline \multirow[t]{2}{*}{ Cause of death } & \multirow[t]{2}{*}{ Sex } & \multicolumn{4}{|c|}{ Testosterone (ng/mL) } & \multicolumn{4}{|c|}{ Estradiol $(\mathrm{pg} / \mathrm{mL})$} \\
\hline & & $\mathrm{n}$ & Median & Min & $\overline{\operatorname{Max}}$ & $\bar{n}$ & Median & Min & $\operatorname{Max}$ \\
\hline \multirow[t]{2}{*}{ Blunt injury } & Male & 19 & 3.42 & 0.54 & 7.50 & 20 & 263 & 20 & 2000 \\
\hline & Female & 5 & 1.14 & 0.32 & 2.78 & 6 & 365 & 203 & 720 \\
\hline \multirow[t]{2}{*}{ Sharp instrument injury } & Male & 6 & 2.56 & 1.92 & 4.56 & 5 & 88 & 78 & 382 \\
\hline & Female & 2 & & 0.32 & 2.78 & 2 & & 129 & 202 \\
\hline \multirow[t]{2}{*}{ Drowning } & Male & 3 & 2.32 & 0.78 & 5.83 & 3 & 91 & 65 & 280 \\
\hline & Female & 1 & & 1.65 & 1.65 & 1 & & 71 & 71 \\
\hline \multirow[t]{2}{*}{ Fire fatalities } & Male & 1 & & 3.78 & 3.78 & 1 & & 114 & 114 \\
\hline & Female & 1 & & 1.26 & 1.26 & 1 & & 20 & 415 \\
\hline \multirow[t]{2}{*}{ Asphyxia } & Male & 3 & 6.28 & 4.26 & 8.15 & 3 & 340.5 & 283 & 20 \\
\hline & Female & 7 & 1.40 & 0.22 & 5.92 & 7 & 533 & 69 & \\
\hline \multirow[t]{2}{*}{ Hypothermia } & Male & 0 & & & & 0 & & & \\
\hline & Female & 1 & & 4.67 & 4.67 & 1 & & 790 & \\
\hline \multirow[t]{2}{*}{ Hyperthermia } & Male & 5 & 5.19 & 1.89 & 10.10 & 5 & 200 & 32 & \\
\hline & Female & 7 & 1.00 & 0.20 & 2.68 & 8 & 215.5 & 20 & 993 \\
\hline \multirow[t]{2}{*}{ Sudden cardiac death } & Male & 3 & 2.79 & 1.98 & 4.42 & 3 & 187 & 70 & 453 \\
\hline & Female & 3 & 1.20 & 1.07 & 1.90 & 3 & 107 & 24 & 441 \\
\hline \multirow[t]{2}{*}{ Other natural death } & Male & 11 & 3.61 & 1.07 & 7.45 & 11 & 367 & 84 & 2000 \\
\hline & Female & 14 & 1.30 & 0.22 & 8.55 & 11 & 192 & 20 & 1317 \\
\hline \multirow[t]{2}{*}{ Total } & Male & 51 & 3.42 & 0.54 & 10.10 & 51 & 278.5 & 20 & 2000 \\
\hline & Female & 41 & 1.20 & 0.20 & 8.55 & 40 & 275 & 20 & 1765 \\
\hline
\end{tabular}

patella for sex estimation (Michiue et al. 2017). However, image analysis does offer some advantages for human sex estimation. These include its utility for analyzing highly decomposed bodies (Kranioti et al. 2009) and bone fragments and/or isolated bones (Croker et al. 2016), and it can easily be updated new data on evolution and/or degeneration (Memarian et al. 2017) .

Previous studies have suggested that testosterone influenced differences in ring finger and index finger lengths, and that this would be expected to apply to a wide range of circumstances (Bijleveld and Baalbergen
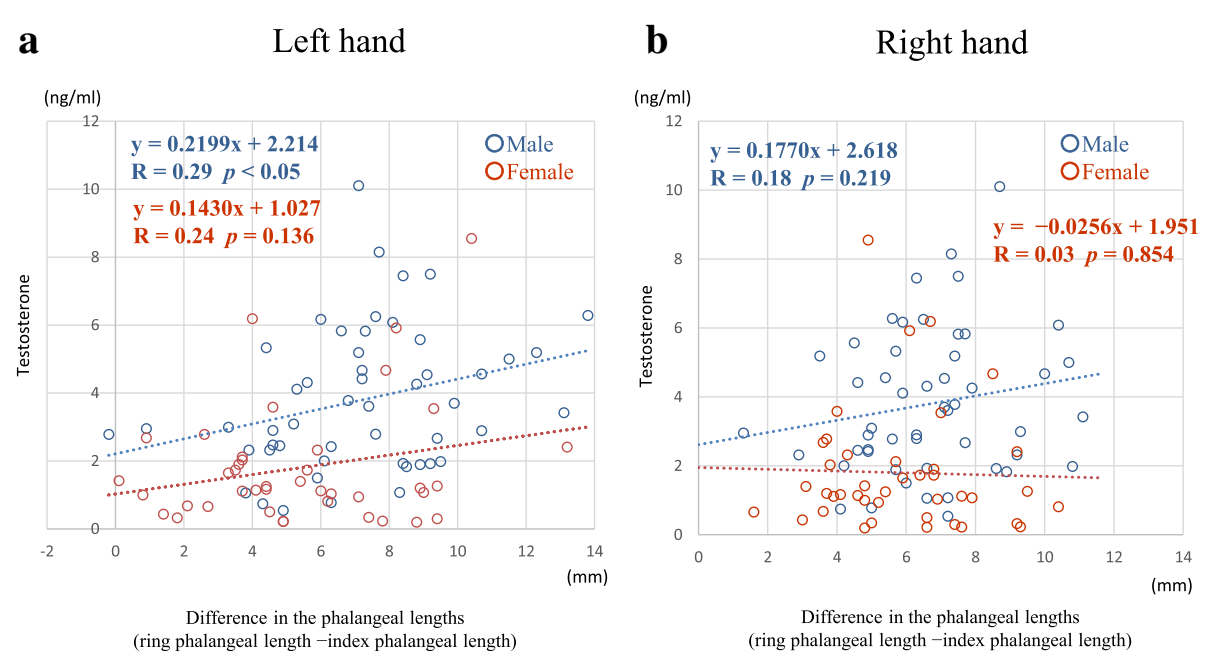

Fig. 5 Correlations between testosterone levels in the right heart serum and the difference in ring and index phalangeal lengths in (a) the left hand and (b) the right hand 
2017; Parkin Kullmann and Pamphlett, 2017). In the present study, measurements of right heart serum levels of testosterone levels in 92 cases of men and women showed higher levels in the men who had longer ring than index finger phalanx lengths.

There was no correlation between finger bone lengths and age. However, except for elderly persons, there were associated with increase in testosterone concentration and the finger lengths. Moreover, a relationship between serum testosterone and $P$ for the left hand was also found although this did not apply to the right hand. The reason for this difference between the hands is unclear, but it may reflect the degree of work performed by the fingers due to handedness, or the possibility that a decrease in age-related testosterone influences is supposed. There were no significant correlations between finger lengths and blood estradiol levels. The correlation between finger length and testosterone levels decreases as individuals become elderly. An explanation for the lack of correlation between finger length and testosterone levels in women is that testosterone may be masked by estrogen in premenopausal women (Matsui et al. 2013) although this masking decreases after the menopause, when testosterone levels have been reported to increase (Matsui et al. 2013) (Burger et al. 2002).

\section{Conclusion}

A value of $6.0 \mathrm{~mm}$ for the ring finger-index finger difference for the left hand distinguished men from women, and these results are affected by testosterone levels. The findings from this report in the field of forensics and paleoanthropology indicated that the CT data-assessed morphometry of the phalanges could be used as an objective index for sex estimation.

\section{Abbreviations}

$\mathrm{CT}$ : Computed tomography; $I$ : The index finger; $M$ : The length of the metacarpal bones in the longitudinal direction; $P+M$ : The total of lengths $P$ and $M_{i} P$ : The length from the bottom prominence to the tip of the distal phalanx; $R$ : The ring finger

\section{Acknowledgements}

Not applicable.

Ethical Approval and Consent to participate.

There are no ethical approval and consent to participate. The need for approval was waived.

\section{Competing interests.}

There are no financial competing interests in our study.

\section{Authors' Contribution.}

T. Ikeda, T. Michiue, and T. Ishikawa analyzed the data and drafted the manuscript. K. Miyamoto, S. Oritani, and T. Ishikawa designed the study, and directed implementation and data collection. N. Tani, and K. Miyamoto collected the data, and K. Miyamoto provided necessary logistical support. Endnotes.

We are pleased to submit the above manuscript for consideration for publication as an original research article in Egyptian Journal of Forensic Sciences.
We believe that the results of this study should provide valuable information for your readers.

The manuscript has not been published elsewhere and is not being considered for publication in another journal. All authors have read and approved submission of the manuscript.

We look forward to learning the results of peer review in due course.

\section{Funding}

There are no funding in our study.

Availability of data and materials.

Our data can be found in the main paper.

Consent for publication.

Not applicable.

\section{Publisher's Note}

Springer Nature remains neutral with regard to jurisdictional claims in published maps and institutional affiliations.

Received: 11 January 2018 Accepted: 10 July 2018

Published online: 14 July 2018

\section{References}

Agnihotri AK, Jowaheer AA, Soodeen-Lalloo AK (2015) Sexual dimorphism in inger length ratios and sex determination - a study in indo-Mauritian population. J Forensic Legal Med 35:45-50

Alarcon JA, Bastir M, Rosas A (2016) Variation of mandibular sexual dimorphism across human facial patterns. Homo 67:188-202

Aldegheri R, Agostini S (1993) A chart of anthropometric values. J Bone Joint Surg $\mathrm{Br}$ 75:86-88

Auerbach BM (2011) Methods for estimating missing human skeletal element osteometric dimensions employed in the revised fully technique for estimating stature. Am J Phys Anthropol 145:67-80

Aycinena D, Baltaduonis R, Rentschler L (2014) Risk preferences and prenatal exposure to sex hormones for ladinos. PLoS One 9:e103332

Bijleveld E, Baalbergen J (2017) Prenatal exposure to testosterone (2D:4D) and social hierarchy together predict voice behavior in bankers. PLoS One 12: e0180008

Burger HG, Dudley EC, Robertson DM, Dennerstein L (2002) Hormonal changes in the menopause transition. Recent Prog Horm Res 57:257-275

Campobasso CP, Introna F (2001) The forensic entomologist in the context of the forensic pathologist's role. Forensic Sci Int 120:132-139

Croker SL, Reed W, Donlon D (2016) Comparative cortical bone thickness between the long bones of humans and five common non-human mammal taxa. Forensic Sci Int 260:104 e101-104 e117

Dettling A, Skopp G, Graw M, Haffner HT (2008) The influence of sex hormones on the elimination kinetics of ethanol. Forensic Sci Int 177:85-89

Djorojevic M, Roldan C, Garcia-Parra P, Aleman I, Botella M (2014) Morphometric sex estimation from 3D computed tomography os coxae model and its validation in skeletal remains. Int J Legal Med 128:879-888

Duyar I, Pelin C (2003) Body height estimation based on tibia length in different stature groups. Am J Phys Anthropol 122:23-27

Ezaki K, Nakagawa M, Taniguchi Y, Nagano Y, Teshima Y, Yufu K, Takahashi N, Nomura T, Satoh F, Mimata H (2010) Gender differences in the ST segment: effect of androgen-deprivation therapy and possible role of testosterone. Circ J4:2448-2454

Giurazza F, Del Vescovo R, Schena E, Battisti S, Cazzato RL, Grasso FR, Silvestri S, Denaro V, Zobel BB (2012) Determination of stature from skeletal and skull measurements by CT scan evaluation. Forensic Sci Int 222(398):e391-e399

Hasegawa I, Uenishi K, Fukunaga T, Kimura R, Osawa M (2009) Stature estimation formulae from radiographically determined limb bone length in a modern Japanese population. Leg Med (Tokyo) 11:260-266

Hishmat AM, Michiue T, Sogawa N, Oritani S, Ishikawa T, Fawzy IA, Hashem MA Maeda H (2015) Virtual CT morphometry of lower limb long bones for estimation of the sex and stature using postmortem Japanese adult data in forensic identification. Int J Legal Med 129:1173-1182

Hishmat AM, Michiue T, Sogawa N, Oritani S, Ishikawa T, Hashem MA, Maeda H (2014) Efficacy of automated three-dimensional image reconstruction of the femur from postmortem computed tomography data in morphometry for victim identification. Leg Med (Tokyo) 16:114-117 
Inamori-Kawamoto O, Ishikawa T, Michiue T, Mustafa A.M, Sogawa N, Kanou T, Oritani S, Maeda H (2016) Possible application of CT morphometry of the calcaneus and talus in forensic anthropological identification. Int J Legal Med 130: $575-585$

Kalichman L, Batsevich V, Kobyliansky E (2018) 2D:4D finger length ratio and radiographic hand osteoarthritis. Rheumatol Int 38:865-870

Kanchan T, Kumar GP, Menezes RG, Rastogi P, Rao PP, Menon A, Shetty BS, Babu YP, Monteiro FN, Bhagavath P et al (2010) Sexual dimorphism of the index to ring finger ratio in south Indian adolescents. J Forensic Legal Med 17:243-246

Kanchan T, Pradeep Kumar G (2010) Index and ring finger ratio--a morphologic sex determinant in south-Indian children. Forensic Sci Med Pathol 6:255-260

Kranioti EF, Vorniotakis N, Galiatsou C, Iscan MY, Michalodimitrakis M (2009) Sex identification and software development using digital femoral head radiographs. Forensic Sci Int 189(113):e111-e117

Krishan K, Kanchan T, Asha N, Kaur S, Chatterjee PM, Singh B (2013) Estimation of sex from index and ring finger in a north Indian population. J Forensic Legal Med 20:471-479

Macaluso P.J Jr., Lucena J (2014) Stature estimation from radiographic sternum length in a contemporary Spanish population. Int J Legal Med 128: 845-851

Maeda H, Fukita K, Oritani S, Ishida K, Zhu BL (1997) Evaluation of post-mortem oxymetry with reference to the causes of death. Forensic Sci Int 87:201-210

Maeda H, Fukita K, Oritani S, Nagai K, Zhu BL (1996) Evaluation of post-mortem oxymetry in fire victims. Forensic Sci Int 81:201-209

Matsui S, Yasui T, Tani A, Kunimi K, Uemura H, Yamamoto S, Kuwahara A, Matsuzaki T, Irahara M (2013) Associations of estrogen and testosterone with insulin resistance in pre- and postmenopausal women with and without hormone therapy. Int J Endocrinol Metab 11:65-70

Memarian A, Aghakhani K, Mehrpisheh S, Fares F (2017) Gender determination from diagnostic factors on anteroposterior pelvic radiographs. J Chin Med Assoc 80(3):161-168

Michiue T, Hishmat AM, Oritani S, Miyamoto K, Amin MF, Ishikawa T, Maeda H (2017) Virtual computed tomography morphometry of the patella for estimation of sex using postmortem Japanese adult data in forensic identification. Forensic Sci Int. https://doi.org/10.1016/j.forsciint.2017.11.029

Ozaslan A, Iscan MY, Ozaslan I, Tugcu H, Koc S (2003) Estimation of stature from body parts. Forensic Sci Int 132:40-45

Parkin Kullmann JA, Pamphlett R (2017) Does the index-to-ring finger length ratio (2D:4D) differ in amyotrophic lateral sclerosis (ALS)? Results from an international online case-control study. BMJ Open 7:e016924

Petrovecki V, Mayer D, Slaus M, Strinovic D, Skavic J (2007) Prediction of stature based on radiographic measurements of cadaver long bones: a study of the Croatian population. J Forensic Sci 52:547-552

Rainio J, Lalu K, Ranta H, Penttila A (2001) Radiology in forensic expert team operations. Leg Med (Tokyo) 3:34-43

Rodriguez S, Gonzalez A, Simon A, Rodriguez-Calvo MS, Febrero-Bande M, Cordeiro C, Munoz-Barus JI (2014) The use of computerized tomography in determining stature and sex from metatarsal bones. Leg Med (Tokyo) 16:252-257

Slizewski A, Schonau E, Shaw C, Harvati K (2013) Muscle area estimation from cortical bone. Anat Rec (Hoboken) 296:1695-1707

Torimitsu S, Makino Y, Saitoh H, Ishii N, Hayakawa M, Yajima D, Inokuchi G, Motomura A, Chiba F, Iwase H (2014a) Stature estimation in Japanese cadavers using the sacral and coccygeal length measured with multidetector computed tomography. Leg Med (Tokyo) 16:14-19

Torimitsu S, Makino Y, Saitoh H, Sakuma A, Ishii N, Hayakawa M, Inokuchi G, Motomura A, Chiba F, Hoshioka Y (2015a) Stature estimation in Japanese cadavers based on scapular measurements using multidetector computed tomography. Int J Legal Med 129:211-218

Torimitsu S, Makino Y, Saitoh H, Sakuma A, Ishii N, Hayakawa M, Inokuchi G, Motomura A, Chiba F, Hoshioka Y et al (2015b) Stature estimation in Japanese cadavers based on the second cervical vertebra measured using multidetector computed tomography. Leg Med (Tokyo) 17:145-149

Torimitsu S, Makino Y, Saitoh H, Sakuma A, Ishii N, Hayakawa M, Yajima D, Inokuchi G, Motomura A, Chiba F (2014b) Stature estimation based on measurements of the sternal medullary cavity using multidetector computed tomography images of Japanese cadavers. Forensic Sci Int 242:299 e291-299 e295

Torimitsu S, Makino Y, Saitoh H, Sakuma A, Ishii N, Hayakawa M, Yajima D, Inokuchi G, Motomura A, Chiba F et al (2014C) Stature estimation based on radial and ulnar lengths using three-dimensional images from multidetector computed tomography in a Japanese population. Leg Med (Tokyo) 16:181-186

Torimitsu S, Makino Y, Saitoh H, Sakuma A, Ishii N, Hayakawa M, Yajima D, Inokuchi G, Motomura A, Chiba F et al (2015c) Stature estimation in Japanese cadavers based on pelvic measurements in three-dimensional multidetector computed tomographic images. Int J Legal Med 129:633-639

Verhoff MA, Ramsthaler F, Krahahn J, Deml U, Gille RJ, Grabherr S, Thali MJ, Kreutz K (2008) Digital forensic osteology--possibilities in cooperation with the Virtopsy project. Forensic Sci Int 174:152-156

Vexler A, Schisterman EF, Liu A (2008) Estimation of ROC curves based on stably distributed biomarkers subject to measurement error and pooling mixtures. Stat Med 27:280-296

Warrington NM, Shevroja E, Hemani G, Hysi PG, Jiang Y, Auton A, Boer CG, Mangino M, Wang CA, Kemp JP et al (2018) Genome-wide association study identifies nine novel loci for 2D:4D finger ratio, a putative retrospective biomarker of testosterone exposure in utero. Human Mol Genet 12 (in press)

Zeybek G, Ergur I, Demiroglu Z (2008) Stature and gender estimation using foot measurements. Forensic Sci Int 181(54):e51-e55

Zhang W, Robertson J, Doherty S, Liu JJ, Maciewicz RA, Muir KR, Doherty M (2008) Index to ring finger length ratio and the risk of osteoarthritis. Arthritis Rheum 58:137-144

\section{Submit your manuscript to a SpringerOpen ${ }^{\circ}$ journal and benefit from:}

- Convenient online submission

- Rigorous peer review

- Open access: articles freely available online

High visibility within the field

- Retaining the copyright to your article

Submit your next manuscript at $>$ springeropen.com 